\title{
Synthesis of ZSM-5 zeolite from diatomite for fluid catalytic cracking (FCC) application
}

\author{
Yang $\mathrm{Li}^{1} \cdot$ Hongman Sun ${ }^{1,2} \cdot$ Rui Feng ${ }^{1}$ Youhe Wang ${ }^{1,2} \cdot$ Fazle Subhan $^{3} \cdot$ \\ Zifeng Yan $^{1} \cdot$ Zhongdong Zhang $^{4} \cdot$ Zhaoyong Liu $^{4}$
}

Received: 12 March 2015 / Accepted: 19 May 2015/Published online: 3 June 2015

(c) The Author(s) 2015. This article is published with open access at Springerlink.com

\begin{abstract}
In this study, ZSM-5 zeolite was successfully synthesized hydrothermally from cheap and easily accessible natural mineral diatomite in the presence of tetrapropyl ammonium bromide. The pore structure, acidic sites and surface features of as-synthesized ZSM-5 zeolite were well characterized by $\mathrm{X}$-ray diffraction, scanning electron microscopy, pyridine-adsorbed Fourier transform infrared spectroscopy, and $\mathrm{N}_{2}$ adsorption. The analysis results revealed that the as-synthesized ZSM-5 zeolite exhibited excellent hydrothermal stability, high specific surface area $\left(223 \mathrm{~m}^{2} \mathrm{~g}^{-1}\right)$ and more acidic cites than diatomite. After mixing ZSM-5 zeolite with a FCC base catalyst, the catalytic performance was evaluated in a micro-fixed bed reactor using vacuum gas oil (VGO) as feedstock. The high surface area and more acidic sites of as-synthesized ZSM-5 zeolite played an important role in the production of light olefins (propylene and butylene) during catalytic cracking of VGO.
\end{abstract}

Youhe Wang

yhewang@upc.edu.cn

$\triangle$ Zifeng Yan

zfyancat@upc.edu.cn

1 State Key Laboratory for Heavy Oil Processing, CNPC Key Laboratory of Catalysis, China University of Petroleum, Qingdao 266580, Shandong Province,

People's Republic of China

2 College of Science, China University of Petroleum (East China), Qingdao 266580, Shandong Province, People's Republic of China

3 Department of Chemistry, Abdul Wali Khan University, Mardan, KPK 23200, Pakistan

4 Lanzhou Petrochemical Research Center, China National Petroleum Corporation, Lanzhou 730060, Gansu Province, People's Republic of China
Keywords Fluid catalytic cracking - ZSM-5 zeolite · Diatomite · Propylene

\section{Introduction}

Zeolites have received much attention for chemical industry and academia owing to their high thermal stability, shape selectivity and high catalytic activity. ZSM-5, a member of the zeolite family with high-silica content has been widely employed in petrochemical catalytic processes, oil refining and environmental protection fields, such as cracking, isomerization, aromatization and alkylation processes [1-6]. Propylene is currently producing from the steam cracking (SC) of light naphtha. However, this process is inefficient to meet the requirements of propylene in the market. Among various alternative sources for propylene production, FCC units are considered as the most promising and largest one [7]. More than $30 \%$ of the worldwide propylene production is from FCC units and this figure will continue to increase [8]. To enhance the propylene yield of FCC units, ZSM-5 zeolite has been used as an additive in industrial practice since its first commercial use in 1983 [9-15]. Because of its unique pore structure, ZSM-5 zeolite can crack selectively gasolinerange linear or mono-branched hydrocarbons to $\mathrm{C} 3-\mathrm{C} 4$ olefins. And its moderate acidity can largely suppress hydrogen-transfer reactions [10].

Generally, zeolites are synthesized from sodium aluminosilicate gel containing various commercial silica and alumina reagents [16-20]. However, due to the rapid increase in consumption of zeolites, the commercial silica and alumina have limitations in terms of product cost, which is undesirable to industries. Thus, cheaper raw 
materials are necessary to minimize the cost of producing zeolites. Fortunately, natural aluminosilicate minerals constitute as one of such materials. Many attempts have been made to the synthesis of ZSM-5 zeolite from kaolin [21], rectorite [22], palygorskite [23] and attapulgite [24]. However, most aluminosilicate minerals in their natural state are inactive and the intrinsic $\mathrm{SiO}_{2} / \mathrm{Al}_{2} \mathrm{O}_{3}$ molar ratio is too low to match the silica-alumina ratio of ZSM-5 zeolite. Hence, the activation of aluminosilicate mineral and addition of highly reactive silicon- and aluminumcontaining chemicals are necessary to solve these problems. It is worth noting that diatomite is an outstanding aluminosilicate material not only because of its low cost but also due to the highly reactive amorphous state of its silica skeletons than other materials, which makes it unnecessary to carry out thermal activation to convert an unreactive state into a reactive one $[25,26]$. In addition, the $\mathrm{SiO}_{2}$ content in diatomite usually in the range of $80-90 \%$, which is beneficial to synthesize high-silica zeolites such as ZSM-5 zeolite. Such attempts are the zeolitization of diatomite, which provide silica- and/or alumina-sources for synthesizing zeolite A [25], mordenite [27], ZSM-5 [28], Y [29] and P [30, 31], etc. Currently, the preparation methods of ZSM-5 zeolite using diatomite as raw material can be classified into two types: in situ and non-in situ methods. In in situ method, one portion of the porous diatomite is used as a raw material, while other one as a matrix to obtain hierarchical porous zeolites. For non-in situ strategy, whole of the diatomite is used as raw material to improve the utilization rate of raw materials and obtain high crystallinity ZSM-5 zeolite. Zhang et al. [32] and Shan et al. [33] successfully synthesized hierarchical porous ZSM-5 zeolite from diatomite by in situ method. However, the relative crystallinity of products and the utilization rate of diatomite were too low. On the other hand, Wang et al. [34] synthesized ZSM-5 zeolite from diatomite by non-in situ method. But, the synthetic process by vapor-phase transformation method consumed more time and increased the difficulties of industrialization.

Herein, to overcome the disadvantages of in situ method such as low degree of relative crystallinity of products and utilization rate of diatomite, we employed non-in situ method to synthesize ZSM-5 zeolite using diatomite as a sole silica source without any other additional chemical silica regent. What's more, due to hydrothermal method being beneficial to accelerate mass transfer rate and heat transfer rate, we synthesized ZSM5 by hydrothermal method instead of vapor-phase transformation method. In the meantime, the fluid catalytic cracking performance of as-synthesized ZSM-5 zeolite was also investigated.

\section{Experimental section}

\section{Materials}

Diatomite (containing $91.4 \mathrm{wt} \% \mathrm{SiO}_{2}, 3.5 \mathrm{wt} \% \mathrm{Al}_{2} \mathrm{O}_{3}$ and $2.2 \mathrm{wt} \% \mathrm{Fe}_{2} \mathrm{O}_{3}$ ) was obtained from Qingdao Chuanyi Diatomite Co., Ltd, China. Tetrapropyl ammonium bromide (containing 98 wt $\%$ TPABr) was provided by Shanghai Cainorise Chemicals Co., Ltd, China. Sodium aluminate, sulfuric acid and sodium hydroxide were purchased from local market.

\section{Synthesis of ZSM-5 zeolite}

First of all, diatomite dried and calcined at $500{ }^{\circ} \mathrm{C}$ for $2 \mathrm{~h}$ was leached with $2 \mathrm{~mol} \mathrm{~L}^{-1} \mathrm{H}_{2} \mathrm{SO}_{4}$ solution at $100{ }^{\circ} \mathrm{C}$ for $4 \mathrm{~h}$ with stirring to get rid of $\mathrm{Fe}_{2} \mathrm{O}_{3}$ and organic matter. Then, the slurry was filtered, washed with deionized water and dried at $100{ }^{\circ} \mathrm{C}$. Finally, the purified diatomite was obtained.

ZSM-5 zeolite was synthesized by hydrothermal pathways. In a typical synthesis, $4.46 \mathrm{~g}$ purified diatomite, $0.18 \mathrm{~g}$ sodium aluminate, $3.21 \mathrm{~g}$ TPABr and $85 \mathrm{~g}$ deionized water were mixed. The final $\mathrm{pH}$ of the mixture was adjusted to 13 using sodium hydroxide under vigorous stirring. After stirred for $1 \mathrm{~h}$ at room temperature, the resulting mixture was transferred into stainless steel autoclave with Teflon-lined for hydrothermal synthesis at $170{ }^{\circ} \mathrm{C}$ for $48 \mathrm{~h}$. The precipitated material was recovered by filtration, washed with deionized water and dried at $100{ }^{\circ} \mathrm{C}$ overnight. After calcination at $550{ }^{\circ} \mathrm{C}$ for $6 \mathrm{~h}$, the as-synthesized sample decomposed organic template was obtained.

HZSM-5 zeolite was prepared by three times ion exchanging with aqueous ammonium chloride at $80{ }^{\circ} \mathrm{C}$ followed by filtration, drying and calcination at $550{ }^{\circ} \mathrm{C}$ for $4 \mathrm{~h}$. Then, the additive containing HZSM-5 zeolite and kaolin was treated in $100 \%$ water vapor at $800{ }^{\circ} \mathrm{C}$ for $4 \mathrm{~h}$. Finally, the composite catalyst was prepared by mechanical mixing HZSM-5 zeolite with ZC7300 catalyst (ZC7300 catalyst is a commercial base FCC catalyst that does not contain any additive [35].

\section{Catalytic performance}

The catalytic performance was carried out in a micro-fixedbed reactor using Shenghua vacuum gas oil (VGO) as feedstock. The catalytic reactions occurred at $500{ }^{\circ} \mathrm{C}$ for $75 \mathrm{~s}$ with $0.8 \mathrm{~g}$ of VGO feedstock in a tubular stainless steel reactor with an inner diameter of $13 \mathrm{~mm}$ and length of $180 \mathrm{~mm}$. The catalyst-to-oil (CTO) ratio in the experiments 
Table 1 Properties of Shanghua VGO used in the evaluation

\begin{tabular}{lc}
\hline VGO properties & Value \\
\hline $\mathrm{H}(\mathrm{wt} \%)$ & 12.60 \\
Conradson carbon residue $(\mathrm{wt} \%)$ & 0.0225 \\
Density $\left(20^{\circ} \mathrm{C}\right)\left(\mathrm{kg} \mathrm{m}^{-3)}\right.$ & 962.70 \\
Saturates $(\mathrm{wt} \%)$ & 58.37 \\
Aromatics $(\mathrm{wt} \%)$ & 27.06 \\
Resins and asphaltenes $(\mathrm{wt} \%)$ & 14.57 \\
\hline
\end{tabular}

was 6. The properties of Shenghua VGO feedstock are listed in Table 1.

The catalytic cracking evaluation was conducted according to the literature [36]. The compositions of gaseous products were characterized by Varian 3800 gas chromatograph. The compositions of liquid products were characterized by simulated distillations gas chromatogram as described by the ASTM D2887 standard to identify the mass contents of gasoline, diesel oil and heavy oil. Coke deposited on the catalysts was combusted after the cracking and the $\mathrm{CO}_{2}$ released was measured using the gas chromatograph.

\section{Characterization}

XRD patterns of samples were collected using PANalytical X' Pert PRO MPD X-ray Diffractometer (XRD) with $\mathrm{Cu}-$ $\mathrm{K} \alpha$ radiation $(40 \mathrm{kV}, 40 \mathrm{~mA})$. The morphologies and element compositions of the samples were measured by scanning electron microscope (SEM-EDS) (S4800, Japan). Nitrogen adsorption-desorption isotherms were obtained on Micromeritics ASAP 2020 (USA) at $-196{ }^{\circ} \mathrm{C}$. The pore size distributions were calculated using DFT method. The micropore volume and micropore surface area were calculated using t-plot methods. The FT-IR spectra of the samples were recorded on Perkin Elmer FT-IR spectrometer (USA) in the range of $4000-400 \mathrm{~cm}^{-1}$ using dried $\mathrm{KBr}$ disk technique. The acidity was measured by pyridineFTIR technique on Nicolet Nexus spectrometer (Termo Nicolet).

\section{Results and discussion}

\section{XRD characterization}

To study the phase structure of the samples, the XRD patterns of diatomite and as-synthesized ZSM-5 are shown in Fig. 1. As seen from Fig. 1, the XRD pattern of diatomite has a diffraction peak at $2 \theta$ of $26.7^{\circ}$ corresponding to amorphous silica with small amount of quartz. Compared with diatomite, the as-synthesized ZSM-5 sample has

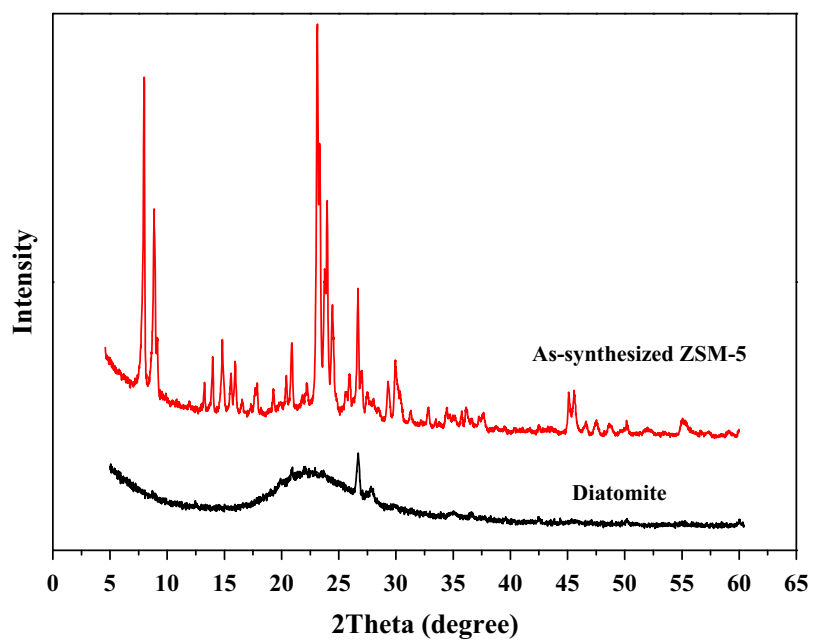

Fig. 1 XRD patterns of diatomite and as-synthesized ZSM-5 zeolite

distinct peaks at $2 \theta$ of $7.9^{\circ}, 8.8^{\circ}, 23.0^{\circ}, 23.9^{\circ}, 24.4^{\circ}$ ascribing to MFI topological structure. This confirms that ZSM-5 zeolite was synthesized from diatomite by hydrothermal crystallization method.

\section{SEM and EDS characterization}

To investigate the morphologies of the samples, SEM images of different magnifications of diatomite and assynthesized ZSM-5 zeolite are presented in Fig. 2. The corresponding elementary compositions of samples are listed in Table 2. The raw material of diatomite shows a disc-like appearance with diameter of 20-50 $\mu \mathrm{m}$ (Fig. 2a). A number of submicron pores in a diameter range of $300-500 \mathrm{~nm}$ are regularly arranged on the disc-like diatomite (Fig. 2b). Compared with the initial diatomite after the zeolitization process, diatomite disc disappeared and a large amount of ZSM-5 zeolite was formed (Fig. 2c). This is a proof of high utilization rate of diatomite for the synthesis of ZSM-5 zeolite. Furthermore, at higher magnification (Fig. 2d), we can observe that most of the crystals are in the form of six prism shape glomerocryst with a particle size range of $2-4 \mu \mathrm{m}$. These phenomena clearly indicate that the large crystals are grown through consuming the diatomaceous silica source. As can be seen from Table 2, the $\mathrm{SiO}_{2} /$ $\mathrm{Al}_{2} \mathrm{O}_{3}$ of as-synthesized ZSM-5 (24.73) is much lower than raw material diatomite (44.34), which means $\mathrm{NaAlO}_{2}$ took part in the synthesis of ZSM-5 zeolite.

\section{$\mathrm{N}_{2}$ adsorption characterization}

Figure 3 depicts the $\mathrm{N}_{2}$ adsorption-desorption isotherms, and pore size distribution of diatomite and as-synthesized ZSM-5 zeolite. The corresponding textural properties are listed in Table 3. 



Fig. 2 SEM images of diatomite $(\mathbf{a}, \mathbf{b})$ and as-synthesized ZSM-5 zeolite (c, d)

Table 2 The results obtained from EDS analysis of samples

\begin{tabular}{llll}
\hline Element (at.\%) & $\mathrm{Si}$ & $\mathrm{Al}$ & $\mathrm{SiO}_{2} / \mathrm{Al}_{2} \mathrm{O}_{3}$ \\
\hline Samples & & & \\
Diatomite & 27.38 & 1.24 & 44.34 \\
As-synthesized ZSM-5 & 24.24 & 1.96 & 24.73 \\
\hline
\end{tabular}

The $\mathrm{N}_{2}$ adsorption-desorption isotherm of as-synthesized ZSM-5 zeolite is the combination of type I and type IV with a H4-type hysteresis loop at a relative pressure ( $p$ / $p_{\mathrm{o}}$ ) of $0.45-0.9$. The sharp increase in the adsorption isotherm at $p / p_{\mathrm{o}}<0.1$ corresponds to the $\mathrm{N}_{2}$ filling in the micropores and the hysteresis loop suggests the presence of mesopores, which can be attributed to the intercrystalline pores between crystallites (Fig. 2d). The $\mathrm{N}_{2}$ adsorptiondesorption isotherm of diatomite is of type IV with a steep uptake at $p / p_{\mathrm{o}}$ of above 0.9 which can be assigned to the existence of macropores in raw material (Fig. 2a). The pore size distribution of as-synthesized ZSM-5 zeolite (Fig. 3b) illustrates the existence of a pore structure with a mesopore size of 2.5-4 nm. Most importantly, the micropore size distribution of the sample is centralized at about $0.54 \mathrm{~nm}$, which coincides with the typical micropore pore size of ZSM-5 zeolite. By comparing the samples of diatomite and as-synthesized ZSM-5 zeolite, it is obvious that the as-synthesized ZSM-5 zeolite has a larger BET surface area $\left(223 \mathrm{~m}^{2} \mathrm{~g}^{-1}\right)$ and micropores pore volume $\left(0.062 \mathrm{~cm}^{3} \mathrm{~g}^{-1}\right)$ than the diatomite. This difference clearly indicates the formation of ZSM-5 crystals from diatomite.

\section{FT-IR characterization}

The FT-IR spectra of diatomite and as-synthesized ZSM-5 zeolite are shown in Fig. 4. As can be seen from Fig. 4, the presence of the ZSM-5 zeolite is identified by the infrared band at $547 \mathrm{~cm}^{-1}$ which is assigned to the five-membered ring of the pentasil zeolite structure. Additional evidence for ZSM-5 is the asymmetric stretching vibration of T-O bond at $1224 \mathrm{~cm}^{-1}$ where $\mathrm{T}$ is $\mathrm{Si}$ or $\mathrm{Al}$, which is attributed to the external linkages (between $\mathrm{TO}_{4}$ tetrahedral groups) and is a structure-sensitive IR band of the ZSM-5 zeolite [36].

\section{Acidity properties and hydrothermal stability of HZSM-5}

The acidity of HZSM-5 zeolite was determined by py-FTIR technique. As shown in Fig. 5, the band at 1548 and $1443 \mathrm{~cm}^{-1}$ are related to the adsorption of the pyridine 

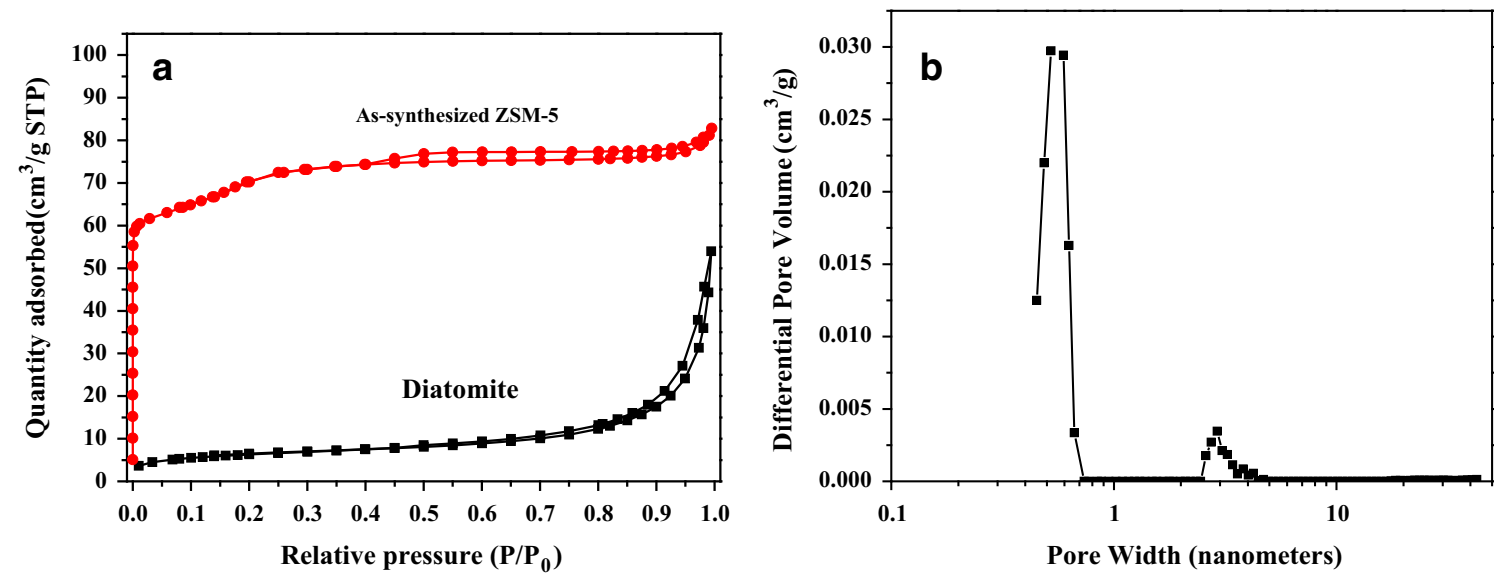

Fig. $3 \mathrm{~N}_{2}$ adsorption-desorption isotherms (a) and pore size distributions (b) of samples

Table 3 Textural properties of diatomite and as-synthesized ZSM-5 zeolite

\begin{tabular}{lclll}
\hline Samples & $\begin{array}{l}\text { BET specific } \\
\text { surface } \\
\left(\mathrm{m}^{2} \mathrm{~g}^{-1)}\right.\end{array}$ & $\begin{array}{l}\text { Micropore } \\
\text { specific surface } \\
\left(\mathrm{m}^{2} \mathrm{~g}^{-1)}\right.\end{array}$ & $\begin{array}{l}\text { Pore volume } \\
\left(\mathrm{cm}^{3} \mathrm{~g}^{-1}\right)\end{array}$ \\
\hline $\begin{array}{l}\text { Diatomite } \\
\text { As-synthesized } \\
\text { ZSM-5 }\end{array}$ & 223 & 5 & 0.08 & - \\
\hline
\end{tabular}



Fig. 4 FT-IR spectra of diatomite and as-synthesized ZSM-5 zeolite

molecules on the Brønsted acid sites and the Lewis acid sites. However, the intensity of peak corresponds to Lewis acid sites is higher than Brønsted acid sites in HZSM-5 zeolite. This is due to the presence of non-framework alumina in ZSM-5 zeolite.

Hydrothermal treatment was conducted to investigate the hydrothermal stability of HZSM-5 zeolite. From Fig. 6, it can be seen that the characteristic peaks of MFI-

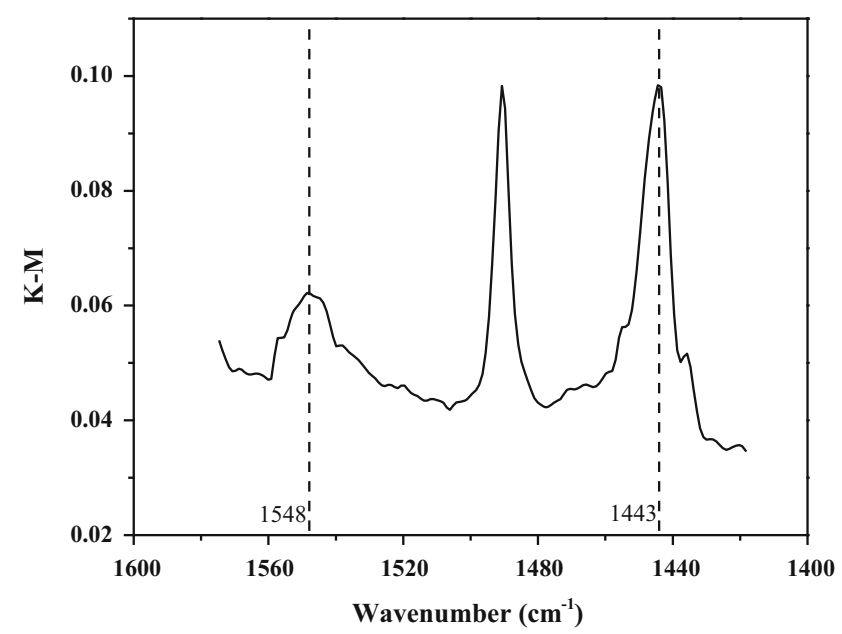

Fig. 5 FT-IR spectra of pyridine adsorbed on HZSM-5 zeolite

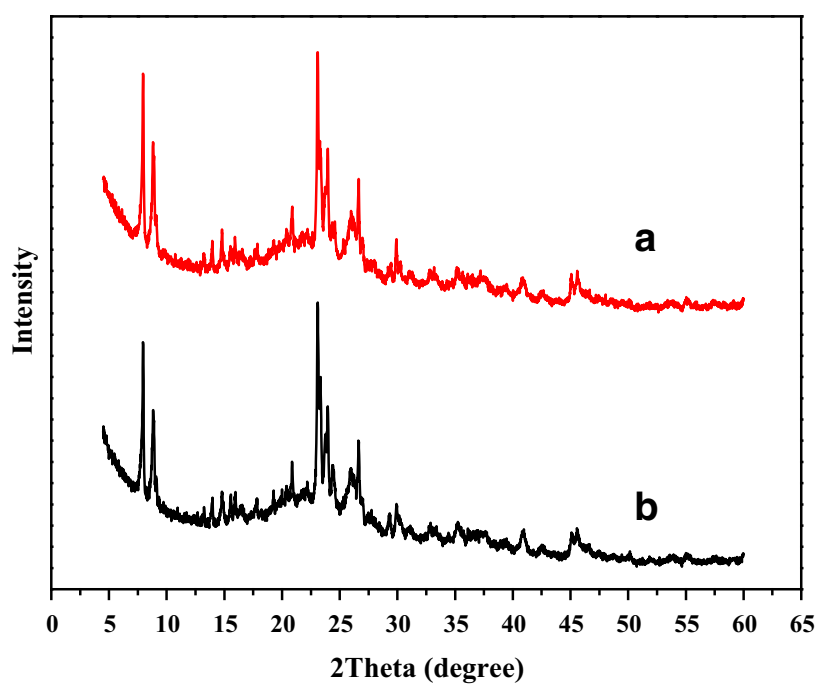

Fig. 6 XRD patterns of HZSM-5 before (a) and after (b) hydrothermal treatment at $800{ }^{\circ} \mathrm{C}$ under $100 \%$ steam for $4 \mathrm{~h}$ 
Table 4 Effect of as-synthesized ZSM-5 additive on the cracking products

\begin{tabular}{lrc}
\hline Catalysts & ZC7300 & $\begin{array}{l}\text { ZC7300 +10 wt\% } \\
\text { as-synthesized ZSM-5 }\end{array}$ \\
\hline Yield of products (\%) & & \\
Dry gas & 2.14 & 2.44 \\
Ethylene & 0.82 & 0.94 \\
Propylene & 5.51 & 7.17 \\
Butylene & 3.02 & 3.99 \\
LPG & 21.35 & 27.06 \\
Gasoline (G) & 23.07 & 18.51 \\
Diesel oil (D) & 17.72 & 18.18 \\
Coke & 5.05 & 3.51 \\
Conversion (\%) & 75.88 & 78.15 \\
\hline
\end{tabular}

structured zeolite are still well preserved in the XRD pattern, indicating that the ZSM-5 zeolite crystals structure are stable up to at $800{ }^{\circ} \mathrm{C}$.

\section{Catalytic evaluation}

As illustrated in Table 4, the effect of as-synthesized ZSM5 on the cracking performance of commercial FCC ZC7300 catalyst was investigated using Shenghua VGO as the feedstock. From Table 4, it can be seen that the addition of as-synthesized ZSM-5 as the additive to the base FCC catalyst increases the yield of light olefins such as propylene and butylene in the FCC process. Compared with ZC7300 catalyst, the composite catalyst containing additional $10 \mathrm{wt} \%$ as-synthesized ZSM-5 zeolite increases the yield of propylene and liquid petroleum gas (LPG) by 1.66 and $5.71 \%$, respectively. Correspondingly, the gasoline yields decreases by $4.56 \%$ and the ratio of $\mathrm{D} / \mathrm{G}$ rise from 0.77 to 0.98 . Furthermore, the yields of the thermal cracking products such as coke decreases by $1.54 \%$.

This phenomenon can be explained from the above characterization results. The HZSM-5 zeolite contains Brønsted acid sites which can supply protons for the FCC reaction. The shifting of proton results in the formation of carbonium ions which favors the FCC reaction towards the formation of light olefins such as propylene and butylene $[37,38]$. It is well know that the FCC reaction is a parallel sequential mechanism. The cracking of the crude oil primarily produce gasoline and diesel oil. However, in the secondary stage, it produces light olefins such as propylene and butylene. As listed in Table 4, the ZC7300 catalyst with HZSM-5 improves the selectivity of the reaction to form secondary cracking products, which results in the increase in the yield of light olefin and decrease in the yield of the primary cracking products gasoline. The decrease of the yields of coke may be attributed to the mesopore structure derived from the interspaces of ZSM-5 crystals that endow the corresponding catalyst with improved accessibility to hydrocarbon molecules and thereafter, lower down the coke selectivity.

\section{Conclusion}

In the present study, ZSM-5 zeolite can be successfully synthesized from diatomite by hydrothermal crystallization method. In comparison with diatomite, the synthesized ZSM-5 zeolite has larger specific surface area and micropore volume. Moreover, ZSM-5 zeolite exhibits excellent hydrothermal stability and appropriate acidity. Compared with the base FCC catalyst, the composite catalyst (containing additional $10 \mathrm{wt} \%$ of as-synthesized ZSM-5 zeolite) exhibits high catalytic activity, superior propylene selectivity, and lower coke selectivity. The yield of light olefin increases by $2.63 \mathrm{wt} \%$. Simultaneously, the yield of gasoline and coke decrease by 4.56 and $1.54 \mathrm{wt} \%$, respectively.

Acknowledgments The work was supported by the Petrochemical Joint Funds of NSFC-CNPC (No. U1362202) and Postgraduate Innovation Project of China University of Petroleum (East China) (NO. YCX2014037).

Open Access This article is distributed under the terms of the Creative Commons Attribution 4.0 International License (http:// creativecommons.org/licenses/by/4.0/), which permits unrestricted use, distribution, and reproduction in any medium, provided you give appropriate credit to the original author(s) and the source, provide a link to the Creative Commons license, and indicate if changes were made.

\section{References}

1. Navrotsky A (1994) Thermochemistry of crystalline and amorphous silica. Rev Mineral Geochem 29:309-329

2. Byggningsbacka R, Kumar N, Lindfors LE (1998) Comparative study of the catalytic properties of ZSM-22 and ZSM-35/ferrierite zeolites in the skeletal isomerization of 1-butene. J Catal 178(2):611-620

3. Venuto PB (1994) Organic catalysis over zeolites: a perspective on reaction paths within micropores. Microporous Mater 2(5):297-411

4. Herrmann C, Fetting F, Plog C (1988) Amine production from methanol and ammonia over ZSM-5 and T-zeolite catalysts. Appl Catal 39:213-226

5. Czaplewski KF, Reitz TL, Kim YJ, Snurr RQ (2002) One-dimensional zeolites as hydrocarbon traps. Microporous Mesoporous Mater 56(1):55-64

6. Chen NY, Garwood WE, Dwyer FG (1996) Shape selective catalysis in industrial applications. Marcel Dekker, New York

7. Radcliffe C (2007) The FCC unit as a propylene source. Pet Technol Q 12(4):45-50

8. Liu H, Zhao H, Gao X, Ma J (2007) A novel FCC catalyst synthesized via in situ overgrowth of NaY zeolite on kaolin microspheres for maximizing propylene yield. Catal Today 125(3): 163-168 
9. Wallenstein D, Harding RH (2001) The dependence of ZSM-5 additive performance on the hydrogen-transfer activity of the REUSY base catalyst in fluid catalytic cracking. Appl Catal A 214(1):11-29

10. Buchanan JS (2000) The chemistry of olefins production by ZSM-5 addition to catalytic cracking units. Catal Today 55(3):207-212

11. Den Hollander MA, Wissink M, Makkee M, Moulijn JA (2002) Gasoline conversion: reactivity towards cracking with equilibrated FCC and ZSM-5 catalysts. Appl Catal A 223(1):85-102

12. Den Hollander MA, Wissink M, Makkee M, Moulijn JA (2002) Synergy effects of ZSM-5 addition in fluid catalytic cracking of hydrotreated flashed distillate. Appl Catal A 223(1):103-119

13. Degnan TF, Chitnis GK, Schipper PH (2000) History of ZSM-5 fluid catalytic cracking additive development at Mobil. Microporous Mesoporous Mater 35:245-252

14. Buchanan JS (1988) Gasoline selective ZSM-5 FCC additives: model reactions of C6-C10 olefins over steamed 55: 1 and 450: 1 ZSM-5. Appl Catal A 171(1):57-64

15. Blasco T, Corma A, Martínez-Triguero J (2006) Hydrothermal stabilization of ZSM-5 catalytic-cracking additives by phosphorus addition. J Catal 237(2):267-277

16. Coker EN, Jansen JC, DiRenzo F, Fajulab F, Martensc JA, Jacobsc PA, Albert SJ (2001) Zeolite ZSM-5 synthesized in space: catalysts with reduced external surface activity. Microporous Mesoporous Mater 46(2):223-236

17. Garcı-Martınez J, Cazorla-Amorós D, Linares-Solano A, Lin YS (2001) Synthesis and characterisation of MFI-type zeolites supported on carbon materials. Microporous Mesoporous Mater 42(2):255-268

18. Kumar R, Mukherjee P, Pandey RK, Rajmohanan P, Bhaumik A (1998) Role of oxyanions as promoter for enhancing nucleation and crystallization in the synthesis of MFI-type microporous materials. Microporous Mesoporous Mater 22(1-3):23-31

19. Choudhury M, Borthakur PC, Bora T (1998) Synthesis and characterisation of silicious mordenite. Indian J Chem Technol $5(1): 1-6$

20. Sun Y, Song T, Qiu S, Pang W (1995) Synthesis of mordenite single crystals using two silica sources. Zeolites 15(8):745-753

21. Pan F, Lu X, Wang Y, Chen S, Wang T, Yan Y (2014) Synthesis and crystallization kinetics of ZSM-5 without organic template from coal-series kaolinite. Microporous Mesoporous Mater 184:134-140

22. Liu H, Cao L, Wei B, Fan Y, Shi G, Bao X (2012) In-situ synthesis and catalytic properties of ZSM-5/rectorite composites as propylene boosting additive in fluid catalytic cracking process. Chin J Chem Eng 20(1):158-166

23. Jiang J, Duanmu C, Yang Y, Gu X, Chen J (2014) Synthesis and characterization of high siliceous ZSM-5 zeolite from acid-treated palygorskite. Powder Technol 251:9-14
24. Zhou X, Liu Y, Meng X, Shen B, Xiao F (2013) Synthesis and catalytic cracking performance of Fe/Ti-ZSM-5 zeolite from attapulgite mineral. Chin J Catal 34(8):1504-1512

25. Ghosh B, Agrawal DC, Bhatia S (1994) Synthesis of zeolite A from calcined diatomaceous clay: optimization studies. Ind Eng Chem Res 33(9):2107-2110

26. Chaisena A, Rangsriwatananon K (2005) Synthesis of sodium zeolites from natural and modified diatomite. Mater Lett 59(12):1474-1479

27. Sanhueza V, Kelm U, Cid R (2003) Synthesis of mordenite from diatomite: a case of zeolite synthesis from natural material. J Chem Technol Biotechnol 78(5):485-488

28. Sanhueza V, Kelm U, Cid R, López-Escobar L (2004) Synthesis of ZSM-5 from diatomite: a case of zeolite synthesis from a natural material. J Chem Technol Biotechnol 79(7):686-690

29. Li T, Liu H, Fan Y, Yuan P, Shi G, Bi X, Bao X (2012) Synthesis of zeolite $Y$ from natural aluminosilicate minerals for fluid catalytic cracking application. Green Chem 14(12):3255-3259

30. Man Z, Meng C (2006) Synthesis of zeolite NaP by diatomite as raw material. Nonmet Mines 29(2):1-5

31. Du Y, Shi S, Dai H (2011) Water-bathing synthesis of highsurface-area zeolite P from diatomite. Particuology 9(2):174-178

32. Zhang K, Liu Y, Zhao J, Liu C (2012) Hierarchical porous ZSM5 zeolite synthesized by in situ zeolitization and its coke deposition resistance in aromatization reaction. Chin $\mathrm{J}$ Chem 30(3):597-603

33. Shan W, Zhang Y, Wang Y, Xia J, Tang Y (2004) Synthesis of meso-/macroporous zeolite ( $\mathrm{Fe}, \mathrm{Al})-\mathrm{ZSM}-5$ microspheres from diatomite. Chem Lett 33(3):270-271

34. Wang D, Liu Z, Xie Z (2008) Preparation of binder-free ultrafine ZSM-5 zeolite monoliths by vapor-phase transformation method. J Inorg Mater 23(3):592-596

35. Abul-Hamayel MA, Aitani AM, Saeed MR (2005) Enhancement of propylene production in a downer FCC operation using a ZSM-5 additive. Chem Eng Technol 28(8):923-929

36. Wang Y, Feng R, Li X, Yan Z (2013) In situ synthesis, characterization and catalytic activity of ZSM-5 zeolites on kaolin microspheres from amine-free system. J Porous Mater 20(1):137-141

37. Wang P, Shen B, Shen D, Peng T, Gao J (2007) Synthesis of ZSM-5 zeolite from expanded perlite/kaolin and its catalytic performance for FCC naphtha aromatization. Catal Commun 8(10):1452-1456

38. Feng H, Li C, Shan H (2009) In-situ synthesis and catalytic activity of ZSM-5 zeolite. Appl Clay Sci 42(3):439-445 